\title{
A PEDAGOGIA DE EXU: EDUCAR PARA RESISTIR E (R)EXISTIR
}

\author{
João Augusto dos Reis Neto ${ }^{1}$ \\ DOI 10.26512/revistacalundu.v3i2.27476
}

\begin{abstract}
Resumo
Este texto é um ato de resistência à lógica colonial a qual fomos historicamente submetidos e trata de discutir as possibilidades da chamada pedagogia exúlica.Parto da noção de que vivemos ainda sob os signos, as marcas e a lógica da colonização, como nos conta Quijano (1998) e Antônio Bispo (2015) e que é no enfrentamento, na resistência, na contracolonização a este regime que produziremos novas epistemologias, dialogando, essencialmente com as epistemologias afro-pindorâmicas (SANTOS, 2015), do Sul, e, desse modo produzir outros modos de ensinar e aprender. Nesse sentido, o objetivo deste texto é apresentar, a partir de um recorte de um estudo mais amplo, as possibilidades epistemológicas de construção de uma pedagogia humanizadora, antirracista, contra-hegemônica, a partir dos valores e princípios do pensamento afro-religioso, centrada na figura do orixá Exu. Por isso, tomamos Exu como signo da resistência epistêmica e da identidade afro-brasileira, como aquele que inaugura outras possibilidades de (r)existência no contexto de racismo e discriminação que vivemos. Ao longo do texto apresentamos elementos constituintes da chamada pedagogia exúlica. Por fim, apresentamos uma síntese do que podemos considerar como a sistematização dessa construção epistêmica.
\end{abstract}

Palavras-chave: Exu. Pedagogia exúlica. Decolonialidade. Epistemologias do Sul.

Estudos decoloniais.

\section{PEDAGOGÍA DE ESHU: EDUCAR PARA RESISTIR Y (R) EXISTIR}

\begin{abstract}
Resumen
Este texto es un acto de resistencia a la lógica colonial a la que hemos estado sometidos históricamente y trata de discutir las posibilidades de la pedagogíaexulica. Partí de la noción de que todavía vivimos bajo los signos, las marcas y la lógica de la colonización, como nos dice Quijano (1998) y Antonio Bispo (2015) y que es en la confrontación, resistencia, contra colonización, a este régimen que produciremos nuevas epistemologías, diálogos, esencialmente con las epistemologías afro-pindoramicas (SANTOS, 2015) del Sur, y por lo tanto producen otras formas de enseñanza y aprendizaje. En este sentido, el objetivo de este texto es presentar, a partir de un recorte
\end{abstract}

\footnotetext{
${ }^{1}$ Universidade Federal de São João Del Rei
} 
de un estudio más amplio, las posibilidades de construir una pedagogía humanizadora, antirracista, contra hegemónica, basada en los valores y principios del pensamiento afroreligioso, centrada en la figura. del orisha Exu. Por lo tanto, tomamos a Exu como un signo de resistencia epistémica e identidad afrobrasileña, como una que inaugura otras posibilidades de (r)existencia en el contexto de racismo y discriminación que vivimos. A lo largo del texto presentamos elementos constitutivos de la llamada pedagogía exulica. Finalmente, presentamos una síntesis de lo que podemos considerar como la sistematización de esta construcción epistémica.

Palabras-clave: Eshu/Elegba. Pedagogía exúlica. Decolonialidad. Epistemologías del sur. Estudios decoloniales.

\section{Padê}

Ofereço-te Exu

O ebó das minhas palavras

Neste padê que te consagra

(Abdias do Nascimento)

Laroyê, Exu! É preciso reverenciar Exu, o primeiro a comer; por isso o nome dessa seção: "Padê", o início. Padê é a comida ritualística, nas tradições religiosas afrobrasileiras de matriz africana, oferecida a Exu antes dos rituais e festas públicas acontecerem. Na tradição dos candomblés, das religiões afro-brasileiras, Exu é sempre o primeiro a ser servido, para que favoreça a comunicação entre o sagrado e os humanos, para que guarde a harmonia daquele local sagrado, para que seja o grande comunicador entre os homens e os orixás. Sendo assim, de modo bastante simbólico, começamos por "despachar a porta", trazemos o padê para que Exu nos seja gentil e nos ajude a contar estas linhas.

Exu, o orixá mensageiro do panteão iorubá, é o princípio dinamizador da vida, das existências, portanto aquele que liga o ayê (a terra) ao orun (“céu”), nosso plano com o plano dos orixás e de nossos ancestrais. Dizem-nos os mais velhos que "sem Exu não se pode fazer nada". Essa fala, sabedoria ancestral do povo de santo, sintetiza a essência de Exu, que de acordo com King e Ribeiro (2015) é considerado o "Senhor da ordem". A própria ordem do universo criado por Olodumare, por isso também é o primeiro a ser reverenciado. Rogamos a Exu que nos veja com bons olhos e que nos dê caminhos de tranquilidade nessas escritas cujo objetivo maior é refletir sobre os modos particulares de se educar no axé (nos terreiros) e sobre a proposição de uma outra 
pedagogia, a qual temos chamado de pedagogia exulíca (REIS NETO, 2019) como modo de (r)existir ao que historicamente tem nos tentado desumanizar. De acordo com Antônio Bispo (2015), historicamente, desde o processo de colonização,

(...) as pessoas afro-pindorâmicas ${ }^{2}$ foram e continuam sendo taxadas como inferiores, religiosamente tidas como sem almas, intelectualmente tida como menos capazes, esteticamente tidas como feias, sexualmente tidas como objetos de prazer, socialmente tidas como sem costumes e culturalmente tidas como selvagens (SANTOS, p. 20-21).

É a partir desta noção de desumanização, trazida pelo autor, é que nos colocamos na resistência. Sobretudo em tempos de retrocessos, de acirramento das desigualdades sociais e a violência contra os povos afro-pindorâmicos.

Este texto é fruto da pesquisa de mestrado que realizei entre os anos de $2017 \mathrm{e}$ 2019. Ele é um retorno às memórias ao mesmo tempo que é a continuidade do que tenho pensado em meu campo de estudo e pesquisa, sobretudo, por estar alicerçado na perspectiva da circularidade (OLIVEIRA, 2005; SOUZA, 2016). De certo modo, ele é uma síntese teórica do que busquei construir durante a minha pesquisa. É, portanto, um estudo teórico sobre as potências que Exu nos oferece para (re)pensarmos a educação.

A circularidade é uma categoria central para o pensamento afro-brasileiro e que nos revela uma outra perspectiva de pensamento, outros modos de ensinar aprender e de pesquisar. Em outras palavras, é uma perspectiva que, de fato, pode nos aproximar de construções epistemológicas e pedagogias contracolonizadoras, no sentido empregado por Santos (2015). Mais adiante, neste texto, apresentarei melhor o conceito de circularidade. Nesse sentido, partimos dos princípios de circularidade, da essência de Exu, da lógica exúlica (SOUZA, 2016), para pensarmos uma pedagogia decolonial, contracolonial que nos ajude a resistir e ressignificar nossas existências de sujeitos violentados pela colonização e pela colonialidade (QUIJANO, 1998; SANTOS, 2015).

Neste texto, então, me dedico a pensar, por meio de Exu, uma pedagogia que nasce das encruzilhadas, como nos conta Rufino Junior (2017), que se ergue como resistência à lógica da colonialidade que historicamente tem nos assujeitado, produzindo em nós a degradação de nossas identidades e culturas. O lócus originário desse pensamento afro-diaspórico da pedagogia exúlica são os espaços fundados e mantidos

\footnotetext{
2 Antônio Bispo dos Santos (2015) ao usar a expressão "afro-pindorâmicas" se refere aos povos e territórios originários da América do Sul (daí a referência à Pindorama "Terra das palmeiras" dos tupiguarani). É utilizada em um esforço e exercício de descolonização da linguagem e do pensamento (SANTOS, 2015, p. 12).
} 
pelas matrizes africanas em nossa cultura, principalmente os terreiros e as narrativas produzidas pelos adeptos das religiões de matriz africana, além do diálogo com pesquisadores/as do tema em questão. Nesse sentido, bebemos também no pensamento de Beatriz Nascimento (1985), por meio do conceito de quilombo, compreendendo-o como múltiplas formas de resistência do povo negro e, assim, olhamos para a proposição de uma pedagogia exúlica como um signo de luta e resistência. Por pedagogia exúlica, então, estamos tratando e nomeando um outro modo de aprender e ensinar. Estamos tratando da proposição de uma pedagogia calcada nas matrizes do pensamento e dos valores afro-brasileiros que reconheça e legitime o saber produzido por estes povos. Em síntese, uma pedagogia que busque, em sua construção, valorizar aspectos fundamentais da cultura e história dos povos afro-pindorâmicos como a ancestralidade, a corporeidade, a oralidade, a circularidade, a relação íntima entre humano-natureza, a arte, além de prezar pela presença alteritária do outro, convivendo com as diferenças. Uma pedagogia que busca romper com a lógica cartesiana e individualista do ocidente, que se volte para o coletivo, para o exercício democrático e pela emancipação e autonomia dos sujeitos.

Neste sentido, nos indagamos o que podemos aprender com Exu para a descolonização dos nossos modos de ensinar e aprender? O que podemos aprender com Exu para a construção de uma outra pedagogia? Essas são algumas questões que tenho feito a fim de pensar a pedagogia exúlica e que estão, em alguma medida, presentes neste texto. Diante disso, o objetivo deste texto é apresentar, a partir de um recorte teórico de um estudo mais amplo, as possibilidades de construção de uma pedagogia humanizadora, antirracista, contracolonial, a partir dos valores e princípios do pensamento afro-religioso, desde a perspectiva iorubá, centrada na figura do orixá Exu. Ao longo do texto discorreremos sobre as categorias/conceitos que dão substância e sustentação a esta proposição.

\section{Ilê Axê: os terreiros como espaços de educação}

O kangbasoke lati kọwọn ti o joko lati kọekọ (Só se levanta para ensinar, aquele que se sentou para aprender) 
O provérbio iorubano que abre esta parte do texto, presente na obra África mítica, de Portugueze Barbosa (2018), traduz, em grande parte, o "pensamento pedagógico" das tradições afro-brasileiras já que nos conta sobre um modo, bastante particular, de aprender e ensinar. Vale destacar que ao me referir às religiões de matriz africana falo, de acordo com Caputo (2012), daquelas tradições que tiveram origem em África e o seu desenvolvimento no Brasil, como o candomblé. Desenvolvimento que foi, ao longo do tempo, tendo diversas influências de outras tradições, religiões e visões de mundo, como por exemplo as matrizes indígenas.

Em relação ao modo particular de ensinar e aprender nos terreiros destacamos o lugar da oralidade, uma vez que ela é o principal veículo de transmissão do conhecimento e do axé (força vital) nos terreiros. Podemos perceber isso nos modos em que se praticam a educação nos terreiros, uma educação do axé, nas palavras de Mãe Regina de Oyá, no documentário "Do que aprendi com as minhas mais velhas" (2017). A palavra, essencialmente oral, é que conduz os aprendizados tanto das crianças quanto dos recém iniciados na religião dos orixás, os iaôs (palavra de origem iorubá que designa o recém-nascido para o orixá). E é sempre na companhia dos mais velhos que estes sujeitos vão se constituindo.

Mãe Beata de Yemonjá, no trabalho de Estela Caputo e Mailsa Passos (2007, p. 105), nos conta: “A palavra é o nosso fogo. Nosso axé. Sem ela não somos nada. Por isso é a oralidade que ensina. A oralidade é o fundamental, foi com ela que chegamos até aqui. A vida inteira eu mantive meu axé através da palavra". Nesse sentido, podemos pensar também na oralidade como categoria de interação da linguagem e de veiculação do axé da palavra. Nos terreiros, a oralidade é a constituição própria do pensamento da diáspora e é a categoria pela qual, na linguagem, o povo de santo constitui sua memória e tradição. A oralidade ultrapassa então a noção clássica de interação do diálogo quando traz à cena os ancestrais, os tempos imemoriais. É o diálogo encarnado nos sujeitos vivendo sua experiência espaço-temporal coletivamente, na/pela alteridade. Além disso, a convivência com outras linguagens, como a gráfica, plástica, compõe a produção da visão de mundo e dos modos de vida dos povos afroameríndios.

A oralidade como marca do pensamento afro-brasileiro, como constituinte da cosmovisão africana e, posteriormente, afro-brasileira também é reafirmado por Hampaté Bâ (2010) quando anuncia que o homem é a sua própria palavra e nela se assenta um testemunho do que ele é. Nesse sentido, já percebemos a primeira categoria 
fundamental para pensarmos a pedagogia exúlica. Isso significa pensar em uma pedagogia em que a fala, a oralidade, tenha igualmente espaço, possa ser uma forma de se aprender e ensinar. Na figura do griot, aquele que conta histórias e ensina por meio delas, está parte dessa construção exúlica, já que é Exu a própria fala.

Retomando a ideia de que o terreiro é também um lugar onde se ensina e aprende, Ekedi Sinha ${ }^{3}$, do Ilê Axé Iyá Nassô Oká - Terreiro da Casa Branca (Salvador, BA), nos conta que o terreiro é um espaço de educação. Para ela, corroborando as contribuições de Conceição (2006) e Nascimento (2016), no ilê se aprende a conviver com a diversidade, com as diferenças e principalmente se desenvolve o espírito coletivo, que é traduzido na egbé (comunidade) onde todos formam uma grande família. Assumimos então, junto destes pensadores, a noção de que o terreiro é um espaço de educação. Além disso, a ideia do coletivo, a família de santo, é fator fundamental na identidade afro-brasileira e afro-religiosa. E é nisso também que mira a pedagogia exúlica, uma pedagogia que preze pelo coletivo, pela cooperação, pela formação para o coletivo.

Para Araújo (2015), o terreiro é um espaço que vai além de práticas religiosas, é, na verdade, um verdadeiro espaço de memórias e histórias do povo afro-brasileiro que legitima e constrói identidades, valores e práticas culturais e processos pedagógicos. Concordamos com o autor na medida em que observamos cada vez mais estes sujeitos contando de suas práticas formativas e educativas em espaços acadêmicos como é o caso do estudo de Botelho (2005). Leite (2006) também nos conta sobre os processos educativos nas casas de axé. Para ele, não restam dúvidas sobre a existência de uma educação ministrada nos ilês. As tradições afro-religiosas, especialmente o candomblé, educam para si e para a sociedade, indo além da "instrução religiosa/litúrgica", contribuindo inclusive para a formação das cidadanias e identidades de seus adeptos, participando necessariamente da produção de um modo de vida, como apontado por Nascimento (2016). "O povo de santo se vale de seus conhecimentos e os transmitem às crianças e até mesmo para os adultos que se iniciam na religião. As estratégias utilizadas possuem como objetivo a inclusão social e exercício da cidadania" (LEITE, 2006, p. 05).

Na literatura, como no trabalho de Araújo (2015), encontramos uma vasta discussão que corrobora essa concepção. O mesmo autor considera o "terreiro como

\footnotetext{
${ }^{3}$ A fala de Ekedi Sinha pode ser vista no documentário "Equede Sinha - a mãe de todos", disponível em: https://www.youtube.com/watch?v=ZEDxFNvKL64\&t=2s.
} 
lugar de diferentes formas de educação e vivências" (ARAÚJO, 2015, p. 38), o que também encontramos no estudo de Caputo (2012) e Nascimento (2016). Isso significa que os processos educativos não estão restritos aos espaços escolares. Obviamente, não perdemos de vista a complexidade desses processos pedagógicos tampouco as suas especificidades, o que nos leva a pensar com bastante cautela em generalizações acerca do tema.

Entretanto, a partir da literatura já apontada aqui, neste texto, também tomo por foco os processos educativos nos terreiros enquanto práticas sociais. Compreender que espaços não-escolares também são espaços onde os processos educativos acontecem é inclusive uma forma de buscar combater o ideário colonial que, uma vez formatando a escola a partir de um ideal ocidental, violenta outros modos de ser/viver/educar como os dos sujeitos adeptos das religiões de matriz africana. Caputo (2012) nos conta que, no contexto escolar, muitas crianças e adolescentes oriundos dessas tradições religiosas estão submetidos ao racismo religioso e são, frequentemente, condenados à invisibilidade. Essa constatação reforça ainda mais a necessidade de pensarmos em formas de transformação e superação dessa realidade discriminatória.

Há então, de certo modo, um consenso na literatura especializada que os terreiros também são espaços educativos, o que contamos, de certo modo, de novidade nesse cenário é a emergência de uma pedagogia que busque inspiração nos princípios e valores civilizatórios da tradição iorubá, na figura de Exu. Uma pedagogia que enfrente o ideário da colonialidade, mirando em uma pedagogia contracolonial, como anuncia Santos (2015). Entretanto, como já anunciado por Rufino (2017), Exu extrapola as noções de decolonialidade, já que ele é o próprio movimento da transformação.

Nesse sentido, lançamos mão da figura de Exu, das narrativas míticas - os itãs e da sabedoria ancestral do povo de santo para a discussão das possibilidades de construção de uma pedagogia arteira, que dança, que ginga, que faz criar a novidade, o riso, o colorido, a arte e que ao mesmo tempo emancipa, leva os sujeitos a serem protagonistas de suas próprias histórias como nos ensina Paulo Freire (2011). A pedagogia exúlica como possibilidade de articulação com os dispositivos legais, como as leis 10639 e 11645/08, que instituíram a obrigatoriedade do ensino de história e cultura afro-brasileira e indígena nos currículos oficiais, para produzir uma mudança sociocultural. Assim, quando tratamos de uma pedagogia exúlica nos espaços educativos tradicionais, como a escola, ela instala o debate sobre a diversidade de visões de mundo, sobre a diversidade epistêmica, racial e religiosa, e indaga os currículos 
colonizados (GOMES, 2012), trazendo estes temas para o cotidiano escolar. É uma possibilidade a mais para a efetiv-ação destas leis no cotidiano escolar.

\section{Por que Exu?}

A minha intenção em falar de Exu é, em certa medida, extrapolar as dicotomias ocidentais de bem-mal, sagrado-profano, já que o próprio Exu é avesso às concepções polarizadoras da moral judaico-cristã construídas pelas sociedades ocidentais ditas "civilizadas". Por isso, ele não pode ser "lido", tampouco "apresentado", como um personagem definido como bom ou mal. Autores como Souza (2016), Kawahala e Góes (2017), Oliveira (2007) apontam que Exu não pode ser compreendido dentro da visão ocidental-cristã e ainda reforçam que, de modo geral, a cultura e religião afro-brasileira também não podem ser lidas a partir deste pensamento. Exu é a oposição ao pensamento cartesiano ocidental (KAWAHALA \& GÓES, 2017), é o próprio movimento de transformação e re-criação epistêmica. Portanto, Exu não cabe na lógica binária do ocidente. Souza (2016) ainda destaca que a imagem de um Exu dual, ligado ao diabo católico, é equivocada, uma vez que a cosmovisão iorubá não dialoga com o sistema de pensamento judaico-cristão ocidental, já que não tem nenhuma figura mítica/mística semelhante ao diabo. Assim, neste texto, reafirmo, busco falar de Exu desde a perspectiva iorubá enraizada em parte do pensamento afro-brasileiro.

Na cultura iorubá, de grande importância e projeção dentro dos cultos afrobrasileiros, como os candomblés Ketu, também conhecida como "nagô" (como são genericamente chamados os povos vindos da região da atual Nigéria), Exu é o orixá da comunicação, da fala e o guardião dos caminhos, o senhor das encruzilhadas. Para os nagôs, ele é o orixá central da trama da vida e do sistema místico, pois é o princípio dinâmico do movimento. Exu é quem movimenta o axé e a própria vida no ayê (terra). Sem Exu não há movimento, sem movimento não há orixá e nem vida para os humanos.

Exu é também o orixá mais controverso do panteão iorubá, seja pela sua proximidade com os humanos, seja pelo seu caráter tipicamente travesso, quase “infantil”" como nos conta o estudo de Ellen Souza (2016). Se pensamos, de acordo com a autora, em um orixá que se relaciona com as crianças, para além da usual e lógica relação feita com os orixás gêmeos Ibejí e as Yabás Oxum e Iemanjá, pensamos em 
Exu. Exu, como princípio de ação do indivíduo, é evidente no comportamento das crianças, no fazer infantil, daí o seu caráter infante.

Além disso, neste texto, buscamos pensar na relação desta divindade com a encruzilhada, com seu caráter de ruptura, movimento e possibilidade. Portanto, ambos, Exu e a encruzilhada, passam ser signos e referências epistemológicas para pensarmos a construção da pedagogia exúlica. Para isso tomo a encruzilhada, desde as referências iorubás, como o lugar em que tudo se pode revelar, no qual tudo se desvela, no qual os caminhos se cruzam tornando-se um caminho de encontro e passagens, que representa a ruptura com a linearidade tão associada à ordem pela visão euro-cristã (RUFINO JUNIOR, 2017; REIS NETO, 2019). Em um dos itãs de Ifá4 (PRANDI, 2001) aprendemos como Exu ganhou o domínio das encruzilhadas embora sua atuação se dê em todos os campos do plano material como ruas, bocas de mata, becos etc. segundo a crença afro-brasileira. Conta-nos o itã que

Certo dia Oxalá pediu que Exu se colocasse em posto na encruzilhada por onde passavam todos os que vinham até a sua casa e lhe deu ordens para não deixar passar aqueles que não lhe trouxessem uma oferenda. Havia muitos humanos a fazer e Oxalá não tinha muito tempo para visitas, tampouco para recolher os presentes que lhe era oferecido. Exu, depois desse tempo ali com o velho Orixá, havia aprendido tudo e já podia ajudar a Oxalá e assim o fez. Exu então recolhia todos as oferendas e entregava a Oxalá, era Exu também que coletava os ebós para Oxalá. Exu fazia bem o seu trabalho e Oxalá permanecia atento ao esforço de Exu. Um dia então Oxalá vendo o trabalho de Exu decidiu lhe recompensar. Oxalá então determinou que toda gente que viesse à sua casa deveria pagar alguma coisa a Exu, quando voltasse também (Adaptado de PRANDI, 2001).

Exu ganhou de Oxalá o direito de ser o "Senhor dos caminhos", aquele que está à frente, na porta, o guarda. Exu ganhou o posto de ser aquele que é o intermediário, o mensageiro entre os homens e os orixás.O mesmo itã também nos conta sobre Exu como o "Senhor da ordem", como nos ensina Babá King e Ronilda Ribeiro (2015). Talvez estes sejam seus maiores atributos na cultura afro-brasileira, o de organizador, comunicador e guardador. A este respeito Prandi (2001) coloca que é de Exu a responsabilidade de levar as oferendas aos orixás, destacando a função de comunicador para além daquela de transporte das oferendas já que ele precisa saber se os orixás

\footnotetext{
${ }^{4}$ Os itãs de Ifá são narrativas mitológicas dos povos de origem Yorubá que contêm os seus valores civilizatórios bem como a sua cosmovisão. Para um aprofundamento no tema ver o trabalho de Reis Neto (2019).
} 
foram, de fato, agradados com a oferenda feita pelos humanos. Desse modo, Exu é fundamental, dentro desta cosmovisão, para a vida e sobrevivência dos humanos. Sem Exu os humanos não recebem as orientações do sagrado podendo, assim, perecer no ayê (terra). "Como os orixás interferem em tudo o que ocorre neste mundo, incluindo o cotidiano dos viventes e os fenômenos da própria natureza, nada acontece sem o trabalho de intermediário do mensageiro e transportador Exu" (PRANDI, 2001, p.50).

A encruzilhada é um lugar de intercessão, cruzamento, onde as possibilidades se encontram, onde se materializam os múltiplos caminhos a serem percorridos, tanto no plano material quanto no subjetivo/místico. Aquilo que se transmuta em possibilidade, em multiplicidade, abertura e diálogo. A natureza de Exu é a própria encruzilhada. É na encruzilhada que se instala a possibilidade de um novo caminho, cruzando com tantos outros, materializando a inversão da lógica hierarquizante de etnias, culturas, religiosidade etc. O caráter múltiplo e polifônico de Exu rompe com uma visão eurocêntrica que se expressa através de um discurso unívoco, e de certa forma, nas palavras de Bakhtin (2011), como um discurso monológico. Refiro-me aqui, quanto ao discurso unívoco e monológico, ao discurso epistêmico hegemônico produzido historicamente pelo Norte. Discurso baseado sobretudo no universalismo europeu (KAWAHALA \& GÓES, 2017) que nada conta das experiências, visões de mundo e vivências dos povos afro-pindorâmicos.

Exu e a encruzilhada também podem ser pensados como uma forma de transgressão da forma secular colonizadora de contar a história do continente africano, por conseguinte a história do Brasil e dos afro-pindorâmicos, suas culturas e suas religiosidades, por se tratar de figuras que são representações das tensões históricas, das múltiplas discussões, dos acordos, divergências, etc. Apresentam-se também como a representação da história conflituosa dos afro-brasileiros desde a diáspora e a resistência marcada por inúmeros conflitos e formas de resistir e (r)existir. A encruzilhada como palco da contradição oferece-nos uma imagem que versa sobre a desmistificação da passividade do povo negro desde a escravidão até a contemporaneidade. Neste sentido, retomando o pensamento de Beatriz Nascimento (1985), Exu e a encruzilhada podem ser lidos como signos da resistência negra, inerentes à ideia de quilombo elaborada pela autora.

Pensar sobre os atributos de Exu e da encruzilhada, da potência que eles podem representar no contexto educativo, é bastante profícuo uma vez que isso pode nos ajudar também a reelaborar nosso olhar sobre as questões étnico-raciais. Isso porque Exu, o 
signo indivisível da multiplicidade, pode ampliar a nossa compreensão de alteridade, a noção do "outro", que é, em essência, fundamento para a construção do "eu". É neste reconhecimento do outro, como fundamento para a existência do eu, é que se assenta a possibilidade de criação de um outro olhar para as relações étnico-raciais. Fomenta a construção de uma identidade que é fundamentada na diversidade e na diferença étnica e cultural.

A encruzilhada, portanto, na figura de Exu, é um grito de resistência à lógica da colonialidade, forjada no bojo das violências coloniais, que persistem até hoje em nossa estrutura social (QUIJANO, 1997), o carrego colonial nas palavras de Rufino (2017), ocupando lugares no congresso nacional e avançando sobre a nossa educação, em infames projetos como o "escola sem partido". A valorização das sabedorias ancestrais, a horizontalização das relações nos espaços educativos e o reconhecimento do "outro" é o que podemos considerar também como princípios para a construção da pedagogia exúlica.

Exu é, nesse contexto, a voz que rompe a narrativa colonial unívoca da nossa história e as formas de se compreender os modos de aprender e ensinar, e, na encruzilhada de saberes, de conhecimentos ancestrais, do cruzamento de visões de mundo distintas, traça as possibilidades para novas formas de se construir a própria educação. Ele é a síntese do processo de resistência dos afro-brasileiros à dominação colonialista, que após os anos da colonização se vale hoje das estruturas políticas ditas “democráticas" e das instituições para manter a dominação que se expressa hoje também nos modos de se fazer ciência/pesquisa.

Dizer isso significa compreender que as estruturas de produção do conhecimento ainda são e estão vetadas aos sujeitos afro-pindorâmicos e que isso implica na invisibilização destes sujeitos desaguando em um verdadeiro epistemícidio (CARNEIRO, 2005). Epistemicídio, a partir das ideias da autora, como uma agência branca que produz a anulação, a invisibilidade, o sufocamento dos saberes produzidos pelos chamados sujeitos subalternos. É a morte destas epistemologias, que são, por sua

\footnotetext{
${ }^{5}$ Escola sem partido é um projeto político-ideológico, que se deseja como legislação pelo projeto de lei (PL) 7.180/14, oriundo de setores conservadores e reacionários da política brasileira. O projeto de lei, de autoria do Deputado Erivelton Santana, versa sobre aquilo que chamam de "doutrinação ideológica", que, em tese, buscar impedir o/a professor/a tratar de temas considerados "ideológicos" como a questão de gênero, da diversidade sexual, a democracia etc. O projeto, que também ficou conhecido como lei da mordaça, ganhou visibilidade com a eleição de inúmeros parlamentares de direita favoráveis à ideia, como o próprio presidente da república. Em nossa leitura, o projeto é mais uma tentativa de silenciamento e violência contra sujeitos e setores progressistas da sociedade que buscam e lutam pelo debate democrático.
} 
vez, revolucionárias. "E, ao fazê-lo (silencia-los), destitui-lhe a razão (destes povos), a condição para alcançar o conhecimento "legítimo" ou legitimado. Por isso o epistemicídio fere de morte a racionalidade do subjugado ou a sequestra, mutila a capacidade de aprender etc." (CARNEIRO, 2005, p. 97, grifo nosso). Entretanto, assim como Exu, estes sujeitos, nas frestas, nas dobras do tempo, nos espaços que criam, também nas instituições, buscam contar sobre seus saberes, seus modos de vida, sua visão de mundo, colorando inclusive para recontar suas próprias histórias. Exu é então o orixá que representa um projeto contra-hegemônico de educação e pedagogia, que opera na contramão da lógica ocidental de polarização da dualidade reducionista cartesiana.

Por isso mesmo é Exu a nossa opção para pensar uma pedagogia contracolonial, decolonial que busque se firmar na humanização, na rebeldia, na contradição, na diversidade, na alteridade e no diálogo. Por isso é ele o eleito para ser o assentamento dessa (outra) pedagogia. Assentamento, no sentido de reunir importantes elementos míticos, místicos e empíricos, como a oralidade, a corporeidade, para pensar na pedagogia exúlica. Assentamento, então, aqui é utilizado, metaforicamente, para se compreender a congregação destes diferentes elementos epistêmicos que resulta na construção de algo novo, uma terceira margem além das fronteiras que já existem em cada um desses elementos.

\section{Romper a "lógica" não significa impedir o diálogo}

Exu matou um pássaro ontem com a pedra que só arremessou hoje (Pierre Verger, 2011)

Romper a "lógica" (cristã,ocidental) não significa impedir ou romper o diálogo. Ao contrário, significa potencializá-lo. Exu é quem recria e inspira nossos olhares e formas de pensar/ver o mundo, novas formas de compreender e narrar a nossa história, a história do Brasil e da própria educação em sua dimensão humanizadora. Exu, neste contexto, é isso, uma divindade-ideia-conceito que rompe com a tradição e as visões ahistoricizante (AREDA, 2008) e, por isso, nega dualidades reducionistas e não cabe no binarismo colonial do ocidente. Entretanto, romper com a lógica colonial, que se coloca como verdade universal, não significa impossibilitar o diálogo entre as diferenças e os diferentes. Exu é justamente a unidade que congrega a multiplicidade. Exu é a força da 
subversão, potência para a mudança, como se diz nos terreiros "é Exu que faz o erro virar acerto e o acerto virar erro". Por isso Exu nos inspira a criar uma outra epistemologia, uma outra lógica e uma outra ordem, que venho chamando, a partir de minhas leituras, inspirados nos estudos de Araújo (2015), Souza (2016), Oliveira (2005, 2009), de exulíca.

Isso significa dizer que Exu é um movimento de ruptura ao mesmo tempo em que é deslocamento e encontro. Três grandes eixos que me fazem pensar na lógica e ordem exulíca. Ruptura porque, com seu caráter disruptivo, Exu é uma das alternativas decoloniais à hegemonia e ao monologismo do pensamento colonial, nos apresentando a multiplicidade de modos de olhar e conceber o mundo. Neste sentido evocamos Exu Yangí, a matéria primordial da existência, aquele que fora despedaçado, segundo um dos odus de Ifá, em muitos pedaços e que de cada pedaço originou-se um novo ser, outra e nova existência. A ruptura como possibilidade de (r)existência.Yangí, também senhor da transformação do tempo, evoca a nossa ancestralidade, cada pedaço (r)existente torna-se vivo e faz da vida possibilidade, incluindo aí, outras possibilidades epistemológicas.

Deslocamento porque nos auxilia na tarefa de pensar fora dos moldes da colonialidade que ainda estrutura o pensamento ocidental e influencia as nossas formas de aprender e ensinar; e encontro, porque é a partir da ancestralidade, da circularidade presente em Exu que podemos avançar com a re-descoberta do mundo, com e pela memória, revivendo aquilo que estava de fora, na margem do pensamento ocidental pela colonialidade. Desse modo, a lógica exulíca (SOUZA, 2016) como algo fundado no princípio da continuidade, humano e sagrado juntos, o cotidiano está integrado ao sagrado. Essa ideia também congrega a ideia da circularidade em Exu, o que nos permite compreender também o princípio da continuidade, algo que não se esgota na resposta pronta. No processo de ruptura-deslocamento-encontro, a ancestralidade, tomada desde o pensamento afro-brasileiro, é um princípio fundamental, tendo em vista que ela não se limita aos laços consanguíneos, tampouco familiares; ao contrário, ela arregimenta um modo de vida, sistematiza as relações e, na diáspora, se materializa nas comunidades de terreiro e também se estende aos demais grupos raciais que assumam os valores africanos (OLIVEIRA, 2009).

Além disso, a ancestralidade

protagoniza a construção histórico-cultural do negro no Brasil e gesta, ademais, um novo projeto sócio-político fundamentado nos princípios 
da inclusão social, no respeito às diferenças, na convivência sustentável do Homem com o Meio-Ambiente, no respeito à experiência dos mais velhos, na complementação dos gêneros, na diversidade, na resolução dos conflitos, na vida comunitária entre outros (OLIVEIRA, 2009, p.3-4).

A ancestralidade passa a ser um modo de inserção no tecido social, também pela linguagem, permitindo o acesso a diferentes modos de conceber e olhar para o mundo, para si e para o outro. Ela, então, se configura como epistemologia capaz de gerar estruturas sociais que podem confrontar o modo único de conceber e organizar a vida, bem como a produção do mundo contemporâneo (OLIVEIRA, 2009). Assim, pensar em uma epistemologia e pedagogia exulíca para educar é buscar nas raízes do pensamento afro-brasileiro, nas marcas dos africanos e africanas em nós, traduzidos, sobretudo, nas religiões afro-brasileiras e seus princípios, na ancestralidade, uma outra forma de olhar para o mundo, para o conhecimento e para a educação, propriamente dita. A lógica exulíca, então, se apresenta como um aporte teórico-conceitual para pensarmos as possibilidades de criação de rotas para o enfrentamento da lógica ocidental branca cristã, da criação do pensamento, da produção do conhecimento, dos modos de conhecer, educar.

Obviamente não tenho uma leitura romântica ou ingênua sobre esta questão, quando tratamos de propor um outro olhar pedagógico, outro modo de educar. Quando lanço mão dessas reflexões não suponho, de modo algum, a substituição de um modo dominante por outro, por assim dizer. Ou seja, assim como bem coloca Rufino Junior (2017), não estamos sugerindo que se substitua uma concepção cristã, ocidental, por uma nagô. O que proponho aqui é pensar nas dobras do tempo, nos meandros do tecido social político e institucional que vivemos, outras possibilidades que possam contribuir com a emancipação de nossos/as estudantes, que contemplem a diversidade étnica e cultural do nosso povo e que respeitem as múltiplas identidades, como as dos sujeitos afro-pindorâmicos. Destaco ainda que um pensamento exúlico não se limita à questão da academia e/ou da epistemologia, antes, porém, oferece-nos uma outra referência de pensamento para, inclusive, refletir sobre as nossas relações cotidianas, de poder, de conhecimento, de trabalho. Tal concepção oferece-nos um caminho para nos descolonizarmos. Cabe, então, destacar que esse movimento de aliar um olhar da academia à visão exulíca é o que venho pensando, acompanhado de muitos outros pensadores e pensadoras, como parte dos processos de descolonização. É ruptura e 
anúncio, movimento contínuo no qual as fronteiras de cada um desses olhares não encerram o alcance de uma ou outra ideia.

Exu é o princípio dinamizador do universo, aquele que tudo organiza, faz circular a vida. Em iorubá, de acordo com Sodré (2008), Esù significa “esfera”, que simboliza a criação, o princípio que gera tudo. Significa também renascimento, criação pela novidade, circularidade. Desse modo, é possível tomá-lo como aquele que inspira novos olhares para concepções de ciência, de conhecimento, de valores, de educação e de narrativas da História há muito sedimentadas em nós, por meio de um ideário colonial secular, sobretudo no campo da educação.

Trata-se, portanto, de uma revolução cotidiana, nos mais diversos âmbitos da experiência social, e pessoal, bem como nos cursos de formação de educadores e educadoras, nas salas de aula, nos espaços de gestão e formulação de políticas públicas e nos demais espaços educativos como os terreiros. Nesse sentido, Nilma Lino Gomes ao se referir ao movimento de descolonização, em relação ao currículo, aponta que este movimento exige "mudanças de representação e de práticas. Exige questionamento dos lugares de poder. Indaga a relação entre direitos e privilégios arraigada em nossa cultura política e educacional, em nossas escolas e na própria universidade” (GOMES, 2012, p.100). Este desafio se coloca frequentemente para aqueles/as que ousam repensar a ordem hegemônica, construída pelo ideário colonial capitalista desde a sua invenção moderna como um padrão de poder mundial, conforme nos conta Quijano (1998; 2005), e instalada em nossa sociedade, pois isso significa, em instância maior, repensar a própria sociedade e a reconstrução do nosso povo, historicamente expropriado. Como padrão de poder, a lógica capitalista hierarquiza os humanos, pela ideia de raça, e assim os torna "aptos" à exploração, sendo o padrão branco, europeu, cristão. Por outro lado, acredito que este movimento não é possível sem enfrentamento, nem se concretizará sem resistência daqueles grupos resguardados em suas mil formas de privilégio. Por isso, enfrentar as resistências a essa transformação ética-política-social que buscamos, processualmente, na história do nosso povo, é reconstruir a própria educação, as formas de ensinar e aprender. É dar sentido às nossas existências ainda marcadas pela colonização.

Retomando a discussão sobre a figura de Exu, é preciso ainda destacar que ele, como bem coloca Renato Ortiz (1999), se mantém como o último orixá negro, portanto, como resistência e possibilidade de (r)existência. E é este o aspecto que mais me interessa em Exu, pois ele é a possibilidade da resistência concreta, é a força-motriz do 
universo e da dinâmica da vida, a vitória da vida sobre a morte, a vitória da esperança sobre a violência. Exu é aquele que não se submeteu e nem sucumbiu à colonização, que foi, também, simbólica, atuando, inclusive, na estética das divindades. Exu resistiu ao processo de embranquecimento dos orixás. Muitos ganharam feições e perfis brancos europeizados como foi o caso de Iemanjá, que na construção de uma imagem "brasileira” perdeu suas características africanas, assimilando-se a mulheres brancas. Exu se manteve, portanto, como aquilo que já considerei, chamando-o de "quilombo moderno", pensando também nos sentidos trazidos por Beatriz Nascimento (1985), aquele que guarda o elo com a ancestralidade africana, que traz à memória as origens do povo de santo, e, ao mesmo tempo, do próprio povo brasileiro. Ele amplia nossas possibilidades de conhecer, pensar, criar. É a própria renomeação do mundo, (r)existência.

Neste sentido, Exu, em sua natureza comunicadora, é que dá corporeidade a estas palavras-motrizes, de sentidos múltiplos que se re-criam por meio do diálogo responsivo e que podem gerar muitos outros sentidos para a compreensão deste texto. Corporeidade, também outro princípio que orienta a pedagogia exúlica, que preza pelo movimento, pela expressão do corpo, pela dança ancestral do povo de santo que no rito revive o mito, resiste e recria suas existências.

Exu é a palavra encarnada, no corpo inteiro, transmuta-se em dialogismo e aparece como símbolo (e signo) do rompimento com o "monologismo" ocidental branco, portanto, rompe com o silenciamento do outro, amplia as possibilidades de diálogo com o diferente. Ele encarna a polifonia bakhtiniana (BAKHTIN, 2008) como outras formas de produção do conhecimento, de "outras vozes" na construção das narrativas históricas e culturais e na construção de subjetividades e sujeitos. "Exu lida de perto com os polos opostos da existência e tem a prerrogativa de subverter a ordem das coisas" (SERAFIM \& GONZAGA, 2014, p.12). E isso tudo tem que ver com uma perspectiva descolonial, pois, como dito por Kawahala (2014), Exu é a possibilidade de ruptura com as epistemologias eurocêntricas, é uma possibilidade epistêmica decolonial possível, tanto pelo seu caráter disruptivo quanto por sua potência de criação.

\section{Exu, o pedagogo}


Ao falarmos de uma pedagogia que se coloca como resistência é preciso, antes, considerarmos o cenário histórico-cultural em que ela se localiza(rá). Nesse sentido, é preciso ter em mente o regime de colonialidade ao qual (ainda) estamos submetidos, conforme aponta Quijano (1998). Lugones (2008) ainda discorre sobre a violência da modernidade colonial quando nos conta sobre o alicerce deste sistema. Segundo a autora, a modernidade colonial teve como alicerce a dicotomia entre humanos e nãohumanos, e, nessa perspectiva, as mulheres, os indígenas e os negros não eram/são considerados como humanos. Isso, vale destacar, é um argumento que sustenta até hoje a manutenção das relações de desigualdade e exploração no contexto da colonialidade, do capitalismo moderno.

É preciso dizer isso para que possamos compreender que a emergência de novas resistências, inclusive no campo da educação, é uma contrapalavra à lógica da colonialidade, fruto de um processo histórico colonial, encabeçado pelos países do Norte. Nesse sentido, a nossa resistência, vale reafirmar, é desde o Sul do mundo (SANTOS \& MENESES, 2010, p.12-13), na perspectiva das epistemologias do sul, buscando falar do nosso lugar, dos povos afro-pindorâmicos (SANTOS, 2015).

O racismo opera, no contexto da colonialidade, como uma forma estrutural e estruturante na manutenção da visão colonial. Isso significa dizer que o racismo contamina todas as esferas da experiência social produzindo os mais diversos efeitos negativos em nossa sociedade, como bem discutido por Lélia Gonzalez(1983). A autora nos conta que o racismo em sua articulação com o sexismo gera efeitos violentos sobre os corpos negros e determina inclusive os lugares que as mulheres negras ocupam (ou podem ocupar) na estrutura social racista. É possível, portanto, constatar que o racismo se ocupa de diversas formas nosso imaginário social e muitas vezes se apresenta de modo sutil e velado. Frequentemente toma formas concretas de violência, por exemplo, o racismo religioso.

Isso faz parte da herança colonial que dilacerou as subjetividades e corpos negros e dos povos originários do Brasil, e cometeu um verdadeiro epistemícidio, nos termos que já anunciamos aqui com Carneiro (2005), em relação aos modos de ver e conceber o mundo dos povos afro-pindorâmicos, e que orientou também os nossos modos de educar. Felipe Cruz (2016), sobre este tema, nos conta os efeitos da colonização sobre a intelectualidade indígena. Para ele ainda há muitas ideias e concepções discriminatórias sobre estes povos e seus modos de pensar e conceber o mundo. Muitas delas ditas já superadas, mas que frequentemente reaparecem no 
discurso acadêmico, mesmo que sob uma nova roupagem. Outra questão é sobre a legitimidade de falar "sobre" os indígenas. Ele aponta que há "pesos" diferentes para o conhecimento produzido por indígenas e não-indígenas. A concepção do autor dialoga ainda com a questão do epistemícidio, proposto por Carneiro (2005), nos fazendo perceber que ele se estende aos povos originários.

Fomos historicamente educados na polarização, na construção de oposições, típicas do pensamento ocidental. Rufino Junior (2015) ainda destaca que a política colonial nos educou sob as "luzes" dos discursos que mantêm, conservam e naturalizam o racismo. Para o autor, é neste cenário que podemos verificar que se pode educar para os mais diversos fins, inclusive para a manutenção desta história. A educação não está descolada do contexto histórico e social, por isso nossa educação, nossos modos de educar, ainda se encontram marcados pela ideologia colonial. Entretanto, como toda prática social, a educação é política, recheada de tensões, disputas e acirramentos nos quais despontam também acordos e negociações. Isso significa dizer que não há um consenso sobre esses "modos coloniais" de educar e que há resistência a estes modos por parte de diversos atores sociais presentes no processo educativo, desde a elaboração e gestão de políticas públicas até a escola, como é o caso também dos terreiros. É resistência, é Exu.

Nesse sentido, como bem coloca Arroyo (2012), estes sujeitos - que estiveram historicamente fora dos espaços hegemônicos de produção do conhecimento (já que criaram e mantiveram seus próprios espaços) e passam recentemente a ocupá-los, no sentido de políticas públicas de acesso a universidades, etc. - rejeitam e negam as narrativas históricas depreciativas de suas culturas, fé, religiosidade e passam a requerer o direito de recontar suas histórias, trajetórias, passam a disputar as narrativas sociais e o protagonismo das mesmas, como bem aponta Cruz (2016).

Estes sujeitos reafirmam seus anseios, passam a exigir epistêmica e politicamente mudanças na estrutura social e assim continuam a construir um processo de resistência e de transformação. Esses processos implicam na necessidade de reconstrução de um projeto educativo que seja contra-hegemônico e antirracista e, com isso, experimentam as tensões permanentes desse jogo político-ideológico. Obviamente, este processo não está livre das resistências, dos contra-ataques e das investidas do conservadorismo, da radicalidade de concepções tipicamente coloniais, sobretudo em um ambiente político dominado pelo pensamento neoliberal e neofascista, como temos vivenciado no Brasil (GOMES, 2018). 
Em resposta a isso tudo, educar deve ser um ato de rebeldia, resistência e transformação (FREIRE, 2005; Bell HOOKS, 1997), um ato de "ocupação" dos territórios e latifúndios intelectuais e dos espaços políticos. Por isso, é urgente repensarmos as formas com que temos construídos nossos modos de aprender e ensinar. Rufino Junior ainda afirma que

o racismo/colonialismo esteve estrategicamente presente nos modos
de educação praticados pelas instituições dominantes e - de certa
maneira - permanece nos dias de hoje, seja nas formas concretas ou
simbólicas de violência inferidas aos grupos historicamente
subalternizados. A evidência que ressalto nessa reflexão é a do
colonialismo epistemológico e o fortalecimento de práticas
pedagógicas que contribuíram para o fortalecimento do ideário
colonial (RUFINO JUNIOR, 2015, p.7).

Ao longo do tempo, observamos os cânones da pedagogia colonial ocidental, como as ideias sobre infância e criança do iluminismo, sendo incutidos em nossos currículos de modo natural, quase que sem reação contrária. A isso podemos chamar de uma colonização epistemológica, como nos conta Quijano (1997), no qual permanece o domínio do pensamento ocidental colonizador sobre outras formas de se compreender os sujeitos e os fenômenos educativos, por exemplo, sobre os saberes ancestrais do povo africano e afro-brasileiro.

Estas concepções dominantes são colocadas como verdades absolutas, se legitimam como saberes universais. Rufino Junior (2015) defende ainda que a eficácia desse domínio é tão efetiva que esses conhecimentos - que são somente parte da diversidade de conhecimentos presentes no mundo - são defendidos e outorgados nas instituições educativas como conhecimentos universais (RUFINO JUNIOR, 2015, p.7). A exemplo disto, ainda de acordo com o autor, podemos citar a presença histórica inegável da Igreja como instituição formadora na educação brasileira, desde a fundação da colônia, o que forjou condutas tidas como "ideais" até hoje, o que sufocou e violentou expressões de crença e da intelectualidade africana e afro-brasileira, marcas que evidenciam o serviço prestado pela Igreja à herança colonial.

Diante disso, Exu representa ainda a libertação dos corpos e dos movimentos espontâneos, do ritmo e o florescimento de uma epistemologia (e pedagogia) decolonial, plural, multicor e antirracista. Ao associarmos Exu com a possibilidade de re-criar uma outra pedagogia, que resiste às amarras coloniais, repensamos também os sentidos políticos, práticos, ideológicos ou pragmáticos dados para a profissão da pedagoga e do pedagogo. Por isso, reivindico neste texto uma re-apropriação dos sentidos dado ao 
exercício docente do/da pedagogo/a. Exu é o signo dessa re-apropriação. Com isso, quero dizer que Exu, como pedagogo, concentra em si essencialmente a ideia de educador, no sentido empregado por Paulo Freire (2011), como um valor. Educador no sentido da compreensão crítica do processo de formação. Faço a opção em chamar Exu de pedagogo, embora ele não requeira títulos, porque, ainda pensando em Paulo Freire, é preciso reconhecer e valorizar nossas professoras/es como sujeitos de suas próprias histórias e requerer o respeito historicamente negado a estas/es profissionais.

Assim, trazer Exu como pedagogo, neste texto, implica compreendê-lo como educador, cuja prática está calcada no respeito, na ética e, sobretudo, no diálogo. Exu é o movimento e a criação, condições indispensáveis a uma pedagogia que busque pela formação integral dos educandos, que veja potência na contradição e que não veja na oposição uma polarização simplista. Além disso, pensar na figura de Exu como pedagogo é propor, sob o signo dessa divindade, o reconhecimento e a legitimidade dos saberes construídos pelos povos tidos como subalternos pela colonização, uma forma de justiça cognitiva, nos termos de Santos (2010).

\section{Exu nas escolas: por uma pedagogia decolonial}

Muito já se falou, escreveu sobre Exu, sobre seus aspectos míticos e místicos, estudos descritivos nas ciências sociais, na antropologia, nas ciências da religião. Entretanto, o que desejo sintetizar aqui é um olhar para esta divindade a partir de outro prisma, a sua potência pedagógica. Para Araújo (2015), Exu é quem preside a educação nos terreiros, e por extensão, preside todos os processos educativos conforme já disse neste texto e em outros (REIS NETO, 2019). No mesmo texto, Araújo (2015) ainda assevera que ele é também o senhor dos processos educativos formais, inclusive a escola. Exu está na escola. É preciso aprender com ele. Assim, partindo de outros horizontes epistemológicos, da sabedoria ancestral do povo de santo, da aproximação com as práticas educativas nos ilês (BOTELHO 2005; ARAÚJO, 2015; CAPUTO \& PASSOS, 2007; SOUZA, 2016), buscamos neste texto pensar no que podemos apreender com essas experiências para então repensarmos a própria educação, inclusive a formal.

Rapidamente, gostaria de pontuar duas experiências interessantes a serem pensadas, no contexto da discussão deste texto. A primeira é aprendizagens das 
narrativas míticas dos orixás como formas de construção dos sujeitos, de suas cidadanias, de seus modos de vida, na figura de Mãe Beata de Yemonjá, estudada por Silva (2008) e Caputo e Passos (2007). Pela oralidade se constrói um processo efetivo de educação, de formação cidadã. Outra experiência é a que nos apresenta Júlia Onijasé e Susan Kalik no curta "Do que aprendi com as minhas mais velhas", já mencionado aqui, na qual, pela fala das Yalorixás e adeptos, sobretudo crianças, podemos identificar processos educativos, como a convivência com a natureza e com a comunidade, que podem nos ajudar a construir uma pedagogia contracolonial como a que temos discutido até aqui.

Para isso, para superação destes modelos coloniais, precisamos reconhecer urgentemente que vivemos em uma lógica de exclusão, racista e violenta. Diariamente temos assistido ao massacre de negros e negras, meninos e meninas que perdem suas vidas pela violência, pelo racismo diante da omissão do Estado, como nos contou Abdias do Nascimento em 1978 no "Genocídio do negro brasileiro" e, atualmente, Maíra Brito (2017), quando nos conta sobre as histórias de mães que perderam seus filhos assassinados. Assim, é preciso nos questionarmos sobre a possibilidade de construir uma educação, nos termos que emprega Nilma Lino Gomes (2012), antirracista e descolonizadora.

A Lei 10639/03 é efetivamente a possibilidade mais concreta que temos de realizar isso, por meio dos dispositivos legais como o parecer do CNE 03/2004, as DCN para a educação étnico-racial e o Plano Nacional de Implementação das diretrizes curriculares nacionais para educação das relações étnico-raciais. São aportes que nos permitem repensar o estado em que nos encontramos e as possibilidades de resistência ao mesmo. Gomes (2012) ainda nos conta que esse processo é um dos modos de descolonizar os currículos, não apenas em uma dimensão pragmática, legal, mas também de modo prático na construção do cotidiano escolar.

Não proponho ingenuamente a substituição de um modelo "dominante" por outro, um etnocentrismo por outro, ao contrário, aposto em uma educação que seja plural capaz de se perceber democrática, multicultural, multiétnica e formar cidadãos e cidadãs nessa perspectiva. E Exu é isso, o princípio da multiplicidade congregado na unidade. Ele é o traçado de uma possibilidade de educação, de formação docente, de pedagogia para além da colonialidade e das linhas abissais (SANTOS, 2010).

Obviamente, uma educação construída na perspectiva exúlica, descolonial, tem a ver com as experiências desenvolvidas nos ilês, nas comunidades tradicionais, dialoga 
com elas, mas não é a sua pura reprodução, sobretudo porque Exu é a potência (re)criadora de sentidos, de caminhos. Desse modo, podemos pensar que é na encruzilhada, no desassossego que essas construções vão sendo elaboradas. Certamente essas experiências dependem de condições materiais, concretas, investimentos de recursos e tempos, mas não podemos deixar que estas limitações nos impeçam de pensar as rupturas tão necessárias à educação. Sobretudo porque pensar outras formas de se ensinar e aprender, narrar as próprias vivências e histórias, são formas concretas de resistências, possibilidades de (r)existir.

Pensar em Exu nas escolas significa criar redes de diálogos e partilha de sabedorias e conhecimentos, traçando verdadeiros cruzos, nas palavras de Rufino Junior (2017), entre as experiências educativas dos terreiros e a educação formal. Isso implica, certamente, inventar estratégias de resistência, desenvolver parcerias e olhares coletivos, levando, inclusive para as práticas pedagógicas, os valores e princípios afro-brasileiros, como a coletividade e partilha, experimentados nas comunidades-terreiros. A exemplo disto, destacamos os modos de educar as crianças onde toda a egbé (comunidade) é responsável pela educação de uma criança, não sendo esta atribuída apenas aos progenitores. Esta é uma experiência que pode nos inspirar na construção de uma escola solidária, coletiva e democrática. Com isso, com a participação destes modos de vida construindo a escola, como aponta Araújo (2015) e Nascimento (2016), não se trata de propor ensino religioso, mas sim de ter os valores afro-brasileiros culturais e religiosos respeitados e reconhecidos neste espaço. Trata-se, portanto, de um processo de inclusão. Exu nas escolas é então um processo de resistência, um meio de acolher, respeitar e valorizas os diferentes sujeitos que ali estão e suas culturas, valores e princípios.

\section{Considerações finais}

Falar de Exu é sempre uma alegria. Porém, não posso, enquanto educador, me furtar das tensões que giram em torno dessa divindade, sobretudo quando falamos dos processos de/na educação. É preciso pontuar que Exu é resistência porque há uma perseguição à sua figura, já que ele representa mais do que uma divindade; ele é a síntese do modo de vida e da cosmovisão afro-brasileira. Isso chega na escola. Exu é vetado na escola, sua entrada proibida (ARAÚJO, 2015; CAPUTO, 2012), entretanto, mesmo vetado, barrado, Exu está lá. Ele entra pelas frestas, pelos meandros, se infiltra 
pela boca no corpo dos meninos e meninas que teimam em não obedecer à lógica do assujeitamento, da hierarquização. Exu está lá nas práticas cooperativas insurgentes, disruptivas, de resistência. Está nas ações dos professores e professoras que buscam ampliar o processo de formação para além da instrução por meio do corpo, da fala, da arte. Por isso Exu é a resistência e a possibilidade de recriar as existências neste espaço e na própria sociedade.

Assim, quando proponho pensar uma outra possibilidade de educação, uma pedagogia exúlica, estou mirando também no enfrentamento do imaginário colonial que se perpetua em nossas escolas. Estou mirando no combate do racismo que estrutura historicamente a nossa sociedade, do racismo religioso, no sentido que aponta Oliveira (2017), reafirmando e desvelando o caráter racista da discriminação às tradições afroameríndias para além da questão da intolerância, que muitas vezes, vela o real sentido de uma prática discriminatória.

Entretanto, quando falamos de Exu nas escolas, reafirmo, não estamos propondo que haja a utilização de seus símbolos e/ou representações nas salas de aula, mas sim que haja uma presença simbólica que pode se dar por meio do reconhecimento e valorização daquilo que esta divindade representa para os afro-brasileiros, em seus modos de vida e seus princípios civilizatórios (ARAÚJO, 2015). Isso significa, efetivamente, resistir e ao mesmo tempo (r)existir, recriar este espaço excludente e racista. Práticas pedagógicas que levem em conta o movimento, a oralidade, a corporeidade dos educandos, que valorizem sua origem étnica e cultural, seus modos de vida e cosmovisão, que se façam emancipatórias são potências da pedagogia exúlica.

Por fim, buscando fazer um exercício de síntese, o que trouxe neste texto foram as possibilidades de pensar uma pedagogia que dialoga com as potências do orixá Exu, em diálogo com as práticas educativas dos ilês, com os modos de vida dos sujeitos da diáspora negra, com os princípios e valores civilizatórios dos afro-brasileiros. Sobre estes últimos destacamos a ancestralidade, a oralidade, o senso de coletividade, a corporeidade e, por fim, a circularidade. Valores que são bases para pensarmos uma pedagogia que busque romper com o racismo, com a narrativa unívoca colonial e que se inscreva no tempo histórico como resistência, possibilidade de recriar nossas práticas educativas. 


\section{Referências Bibliográficas}

AREDA, Felipe. "Exu e a reescrita do mundo". Revista África e Africanidades- Ano I, n. 1, v. 1, maio de 2008.

ARROYO, Miguel. Outros Sujeitos, Outras Pedagogias. 1. ed. Petrópolis: Vozes, 2012.

BAKHTIN, Mikhail. Problemas da poética de Dostoiévski. (Tradução de Paulo Bezerra). Rio de Janeiro: Forense Universitária, 2008.

BAKHTIN, Mikhail. Estética da Criação Verbal. $6^{\circ}$ Ed. (Tradução de Paulo Bezerra). São Paulo: Martins Fontes, 2011.

BOTELHO, Denise Maria. "Educação e Orixás: processos educativos no Ilê Axé Iya Mi Agba”. 2005. 126f. Tese de doutorado (Doutorado em Educação) - Faculdade de Educação, Universidade de São Paulo, São Paulo, 2005.

ARAÚJO, Patrício Carneiro. "Entre o terreiro e a escola: Lei 10639/03 e intolerância religiosa sob o olhar antropológico". 2015. 242 p. Tese (Doutorado em Ciências Sociais - Antropologia) - Pontifícia Universidade Católica, São Paulo. 2015.

CAPUTO, Stela Guedes. Educação nos terreiros: e como a escola se relaciona com crianças de Candomblé. Rio de Janeiro: Pallas, 2012.

CONCEIÇÃO, Lúcio André Andrade da. A pedagogia do candomblé: aprendizagens, ritos e conflitos. Dissertação de Mestrado (Programa de Pós-Graduação em Educação e Contemporaneidade)- Departamento de Educação, Universidade do Estado da Bahia. Salvador: UNEB, 2006.

FREIRE, Paulo. Pedagogia do Oprimido. Rio de Janeiro: Paz e Terra, 2005.

FREIRE, Paulo. Pedagogia da autonomia: saberes necessários à prática educativa.São Paulo: Paz e Terra, 2011.

GOMES, Nilma Lino. "Por uma indignação antirracista e diaspórica: negritude e afrobrasilidade em tempos de incertezas". Revista ABPN, v.10, .26, out. 2018.

GOMES, Nilma Lino. "Relações étnico-raciais, educação e descolonização dos currículos". Currículo sem Fronteiras, v.12, n.1, Jan/Abr 2012.

GONZALEZ, Lélia. "Racismo e sexismo na cultura brasileira". Ciências Sociais Hoje, ANPOCS, n. 2, 1983.

HAMPATÉ BÂ, Amadou. “A tradição viva”.In: KI-ZERBO (Editor). História geral da África, I: Metodologia e pré-história da África. Brasília: UNESCO, 2010.

HOOKS, Bell. Teaching to transgress. Education as the practice of freedom. Nova York/Londres: Routledge, 1994. 
KAWAHALA, Edelu. "Na encruzilhada tem muitos caminhos - teoria descolonial e epistemologia de Exu na canção de Martinho da Vila". Tese (Doutorado em Literatura) - Universidade Federal de Santa Catarina, Florianópolis, 2014. 209 p.

KAWAHALA, Edelu; GOÉS, Luciano. “Abdias do Nascimento, um Exu libertador: das teorias deste pensador negro a uma epistemologia de Exu, subsídios para uma psicologia afro-brasileira". Rizoma, v. 1, n.1, jan. 2017.

KING, Sàlámi Síkírù.; RIBEIRO, Ronilda Iyakemi. Exu e a ordem do universo. São Paulo: Editora Oduduwa, $2^{\circ}$ ed., 2015.

LEITE, Vanderlei Furtado. "Candomblé e educação: dos ilês às escolas oficiais de ensino”. 2006. 162 p. Dissertação (Mestrado Interdisciplinar em Educação, Comunicação e Administração) - Universidade São Marcos, São Paulo, 2006.

LUGONES, Maria. “Colonialidad y género”. Tabula Rasa, n.9, julio-diciembre, 2008.

NASCIMENTO, Abdias do. Genocídio do Negro no Brasil: Um Processo de Racismo Mascarado. Editora Paz e Terra, 1978.

NASCIMENTO, Beatriz. "O conceito de quilombo e a resistência cultural negra". Afrodiáspora, nos. 6-7, abr-dez. 1985.

NASCIMENTO, Wanderson Flor do. "Sobre os candomblés como modo de vida: Imagens filosóficas entre Áfricas e Brasis”. Revista Ensaios Filosóficos, v. 13, ago. 2016.

OLIVEIRA, Ariadne Moreira Basílio de. "Religiões Afro-brasileiras e o racismo:contribuições para a categorização do racismo religioso". Dissertação (Mestrado em Direitos Humanose Cidadania). Programa de Pós-Graduação em DireitosHumanos e Cidadania. Brasília: Universidade de Brasília, 2017.

OLIVEIRA, Eduardo D. "Filosofia da Ancestralidade: corpo e mito na filosofia da educação brasileira”. 2005. 353f. Tese de doutorado (Doutorado em Educação) Faculdade de Educação, Universidade Federal do Ceará, Fortaleza, 2005.

OLIVEIRA, Eduardo D. "Epistemologia da Ancestralidade". Entrelugares: Revista de Sociopoética e Abordagens Afins, v. 1, 2009.

ORTIZ, Renato. A morte branca do feiticeiro negro: umbanda e sociedade brasileira. São Paulo: Brasiliense, 1999.

PASSOS, Mailsa Carla; CAPUTO, Stela Guedes. "Cultura e conhecimento em terreiros de candomblé: lendo e conversando com Mãe Beata de Yemonjá". Currículo sem Fronteiras, v. 7, n.2, jul-dez. 2007.

PORTUGUEZ, Anderson Pereira; BARBOSA, Iago de Paula. Contos de uma África mítica: a educação pela oralidade nas religiões de matriz afro-brasileira. Ituiutaba: Barlavento, 2019. 
PRANDI, Reginaldo. Mitologia dos orixás. São Paulo: Companhia das Letras, 2001.

QUIJANO, Aníbal. "Colonialidad del Poder, Cultura y Conocimiento en América Latina".AnuárioMariateguiano, v. 9, n. 9, 1997.

QUIJANO, Aníbal. "Colonialidad del poder, cultura y conocimiento en América Latina”. Ecuador Debate, n. 44, Quito (Equador), agosto de 1998.

QUIJANO, Aníbal. "Colonialidade do poder, Eurocentrismo e América Latina”. In: A colonialidade do saber: eurocentrismo e ciências sociais: Perspectivaslatinoamericanas. CLACSO, Consejo Latinoamericano de Ciencias Sociales. Buenos Aires, 2005.

REIS NETO, João Augusto dos. "Exu e a descolonização da docência: religiosidade afro-brasileira, cinema e a formação de professores(as)”. 2019. 254 p. Dissertação (Mestrado em Educação) - Universidade Federal de São João Del Rei, São João Del Rei. 2019.

RUFINO JUNIOR, Luis Rodrigues. "Exu e a pedagogia das encruzilhadas: Sobre conhecimentos, educações e pós-colonialismo". In: VIII Seminário Internacional As Redes Educativas e as Tecnologias: Movimentos Sociais e a Educação, 2015, Rio de Janeiro. VIII Seminário Internacional As Redes Educativas e as Tecnologias: Movimentos Sociais e a Educação, 2015.

RUFINO JUNIOR, Luis R. "Exu e a Pedagogia das Encruzilhadas”. 2017. 233f. Tese de doutorado (Doutorado em Educação) - Programa de Pós-Graduação em Educação, Faculdade de Educação, Universidade do Estado do Rio de Janeiro, Rio de Janeiro, 2017.

SANTOS, Antônio Bispo dos. Colonização, Quilombos, Modos e Significações. Brasília: INCTI/UnB, 2015.

SANTOS, Boaventura de Sousa. "Para além do pensamento abissal: das linhas globais a uma ecologia dos saberes”. In: SANTOS; MENESES (orgs). Epistemologias do Sul. São Paulo. Cortez, 2010, p. 23-73.

SANTOS, Boaventura de Sousa; MENESES, Maria Paula (Orgs.). Epistemologias do Sul. 2 ed. - São Paulo: Cortez, 2010.

SERAFIM, Vanda F.; GONZAGA, Giovane M. "Exu e as Ciências Humanas no Brasil do século XX”. Caicó, v. 15, n. 34,jan./jun. 2014.

SILVA, Gloria Cecília de Souza e. Os "Fios de Contos" de Mãe Beata de Yemonjá: Mitologia Afro-brasileira e Educação. Dissertação de mestrado apresentada ao Programa de Pós-graduação em Educação da UERJ. Rio de Janeiro: FE/UERJ, 2008.

SODRÉ, Euriclesio B. “Uma poética de Exu em Mário Cravo Neto”. 2006. Dissertação (Mestrado em Programa de Pós-Graduação em Artes Visuais) - Escola de Belas Artes da UFBA. 
SOUZA, Ellen de Lima. "Experiências de infâncias com produções de culturas no Ilê Axé Omo OxéIbá Latam”. 2016. 179f. Tese de doutorado (Doutorado em Educação) Faculdade de Educação, Universidade Federal de São Carlos, São Carlos, 2016.

VERGER, Pierre; CARYBÉ, Hector J. Lendas Africanas dos Orixás. 4. ed. Salvador: Corrupio, 2011.

Recebido em: 04/10/2019

Aceito em: 23/10/2019 